\title{
Environmental influences on fruit and vegetable intake: results from a path analytic model
}

\author{
Angela D Liese ${ }^{1, *}$, Bethany A Bell ${ }^{2}$, Timothy $L$ Barnes $^{1}$, Natalie Colabianchi ${ }^{3}$, James D \\ Hibbert ${ }^{1}$, Christine E Blake ${ }^{4}$ and Darcy A Freedman ${ }^{5}$ \\ ${ }^{1}$ Center for Research in Nutrition and Health Disparities, Arnold School of Public Health, Department of \\ Epidemiology and Biostatistics, University of South Carolina, 921 Assembly Street, Columbia, SC 29208, USA: \\ ${ }^{2}$ College of Education, University of South Carolina, Columbia, SC, USA: ${ }^{3}$ Institute for Social Research, \\ University of Michigan, Ann Arbor, MI, USA: ${ }^{4}$ Department of Health Promotion, Education, and Behavior, \\ University of South Carolina, Columbia, SC, USA: ${ }^{5}$ College of Social Work, University of South Carolina, \\ Columbia, SC, USA
}

Submitted 3 April 2013: Final revision received 13 September 2013: Accepted 23 September 2013: First published online 6 November 2013

\begin{abstract}
Objective: Fruit and vegetable $(\mathrm{F} \& \mathrm{~V})$ intake is influenced by behavioural and environmental factors, but these have rarely been assessed simultaneously. We aimed to quantify the relative influence of supermarket availability, perceptions of the food environment and shopping behaviour on F\&V intake.

Design: A cross-sectional study.

Setting: Eight counties in South Carolina, USA, with verified locations of all supermarkets.

Subjects: A telephone survey of 831 household food shoppers ascertained F\&V intake with a seventeen-item screener, primary food store location, shopping frequency and perceptions of healthy food availability, and supermarket availability was calculated with a geographic information system. Path analysis was conducted. We report standardized beta coefficients on paths significant at the 0.05 level.

Results: Frequency of grocery shopping at primary food store $(\beta=0 \cdot 11)$ was the only factor exerting an independent, statistically significant direct effect on F\&V intake. Supermarket availability was significantly associated with distance to utilized food store $(\beta=-0 \cdot 24)$ and shopping frequency $(\beta=0 \cdot 10)$. Increased supermarket availability was significantly and positively related to perceived healthy food availability in the neighbourhood $(\beta=0 \cdot 18)$ and ease of shopping access $(\beta=0 \cdot 09)$. Collectively considering all model paths linked to perceived availability of healthy foods, this measure was the only other factor to have a significant total effect on F\&V intake.

Conclusions: While the majority of the literature to date has suggested an independent and important role of supermarket availability for F\&V intake, our study found only indirect effects of supermarket availability and suggests that food shopping frequency and perceptions of healthy food availability are two integral components of a network of influences on F\&V intake.
\end{abstract}

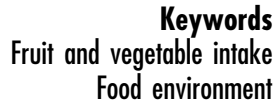

Obesity continues to be a key public health challenge ${ }^{(1,2)}$. Despite repeated changes to the Dietary Guidelines for Americans, food intake trends in the US have not been favourable and fruit and vegetable $(\mathrm{F} \& \mathrm{~V})$ intake still falls markedly short of recommendations ${ }^{(3-5)}$. Possibly due to the limited impact of individual-level interventions on dietary intake and obesity, researchers and policy makers are increasingly interested in upstream factors, such as the built environment and policies ${ }^{(6-13)}$.

Epidemiological research on the built food environment has largely focused on spatial attributes, such as supermarkets in a neighbourhood, using objective data and geographic information systems (GIS) methodo$\operatorname{logy}{ }^{(14)}$. Several studies suggest that poorer supermarket availability is associated with less healthful diets ${ }^{(6,15)}$. A key assumption has been that spatial access is a determinant of dietary behaviour, i.e. the neighbourhood food environment is being utilized ${ }^{(16-22)}$. Whether this is actually the case is relatively unknown. Qualitative research suggests that the choice of a primary food store is influenced not only by proximity but also by financial considerations, availability and quality of specific foods and store characteristics ${ }^{(23)}$. An economic model of food shopping behaviour posits that a household will aim to 


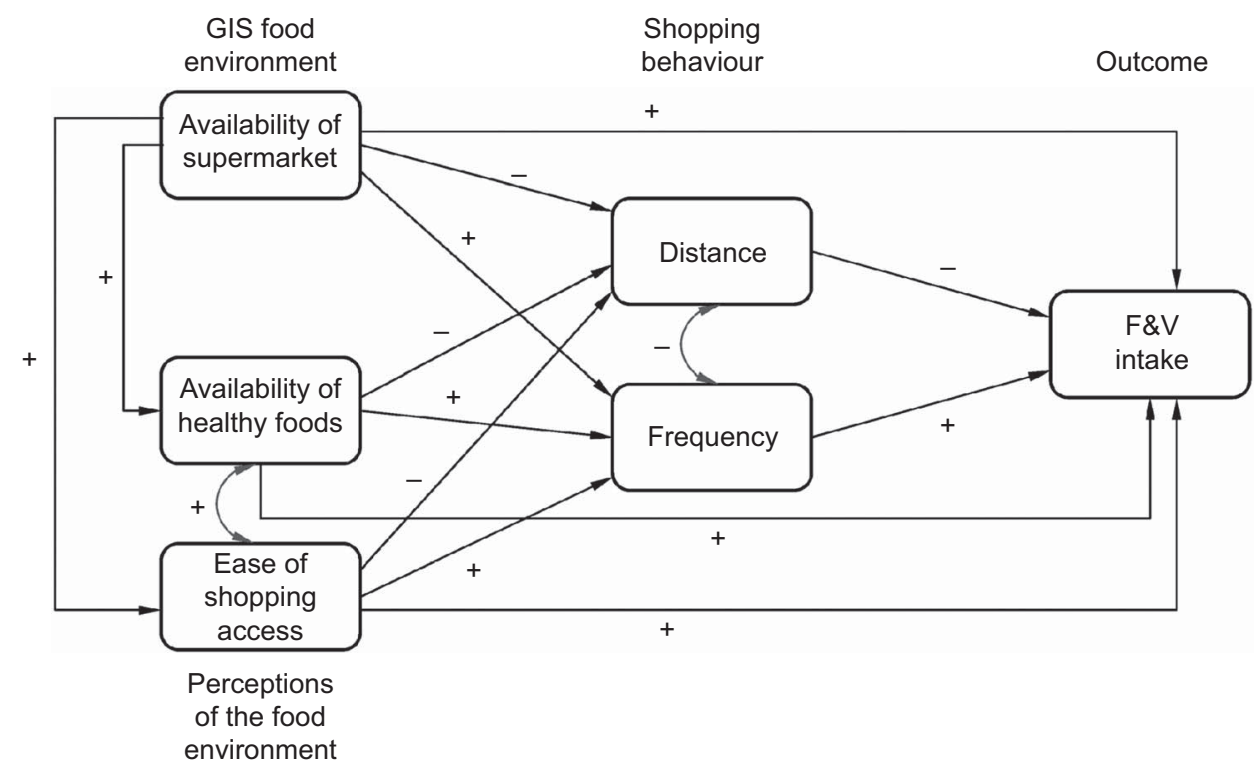

Fig. 1 Conceptual model of environmental influences on fruit and vegetable (F\&V) intake (GIS, geographic information system)

meet its consumption needs while minimizing the travel cost related to distance and the inventory cost ${ }^{(24)}$. Frequency of food shopping is a component of this model, influenced by the household's ability to store foods and the perishable nature of some foods ${ }^{(24)}$. Few studies of general populations have systematically assessed food shopping behaviours and motivations and little is known about the association with $\operatorname{diet}^{(22-32)}$. What is known, however, is that perceptions of the availability of healthy foods in the neighbourhood have been shown to be related to dietary intake ${ }^{(33-36)}$. Perception measures may reflect variation in healthy food availability that is not captured by GIS-based measures ${ }^{(33,34,37-40)}$. It is conceivable that the formation of mental maps of the food environment is a critical intermediate step between living in a built food environment, making decisions about food shopping behaviours and dietary behaviours ${ }^{(16,33,34,37,41)}$.

In totality, research suggests that there is a network of individual and environmental influences that interrelate in their impact on dietary intake. However, there seems to be a lack of studies characterized by comprehensive conceptual frameworks, simultaneously addressing multiple environmental influences on F\&V intake. Most research in this field has used regression analysis, testing individual relationships of single food environment characteristics with dietary outcomes ${ }^{(22,25,29,34,37,42-48)}$. The multitude of important attributes of the food environment described above suggests that statistical approaches that allow more explicit consideration of complex interrelationships may provide new and important insights. Thus, the purpose of the present study was to quantify the relative influence of multiple environmental factors on intake of $\mathrm{F} \& \mathrm{~V}$, including, collectively, objective (GIS-based) and subjective (perceptions-based) measures of the food environment and food shopping behaviours using path analysis. The study's conceptual model, depicted in Fig. 1, was informed by social ecological frameworks ${ }^{(49,50)}$, social cognitive theory ${ }^{(51)}$ and published empirical evidence. In the interest of brevity, our hypotheses about the various relationships are symbolized by arrows in the model. The plus and minus signs above the arrows indicate the directions of the hypothesized associations.

\section{Methods}

\section{Study area and design}

We conducted a cross-sectional study of residents of an eight-county region in South Carolina, USA in 2010. The area was chosen because in 2009 we had validated the entire food retail environment in the eight counties ${ }^{(52)}$. A total of eighty-three unique zip codes fell either entirely or partially within the study area. From these we excluded three zip codes with less than 300 residents, three zip codes serving as post office boxes and thirteen zip codes in which less than $20 \%$ of the zip code's population resided within the eight-county study area, resulting in sixty-four eligible zip codes.

A total of 968 adults were recruited for a telephone survey by the University of South Carolina Survey Research Laboratory. To achieve good spatial coverage, we aimed to interview roughly fifteen respondents per zip code. A simple random sample of residential telephone numbers was selected from each eligible zip code, yielding a total of 2477 residential listed landline telephone numbers. After mailing introductory letters, recruitment calls were placed by trained interviewing staff between April and July 2010. To be eligible, telephone respondents had to be (i) at least 
18 years of age, (ii) the primary food shopper of the household and (iii) English speaking. A total of 968 households were eligible and completed the interview, while 377 telephone numbers were not eligible. Applying the American Association for Public Opinion Research Response Rate Formula $4^{(53)}$, we estimated a response rate of $47 \%$, which is comparable to the $49 \%$ observed among landline households in a recent evaluation of the Behavioral Risk Factor Surveillance System ${ }^{(54)}$. The study was reviewed and approved by the University of South Carolina's Institutional Review Board.

\section{Characterizing the built food environment with a geographic information system}

Similar to the majority of the food environment literature ${ }^{(6,7)}$, we operationalized the spatial access dimension of the food environment with the availability of supermarkets in the study participant's census tract using GIS. Given our study's interest in healthful dietary behaviour, we focused on supermarkets, supercentres, warehouse clubs and large grocery stores (henceforth referred to as 'supermarkets'). These food outlet types had been assigned previously using a name-based approach that relied on recognition of grocery store chains and local knowledge of stores ${ }^{(52,55)}$. The participants' residential addresses were linked to an existing, validated geospatial database of retail food outlets, which contained the exact locations (determined by GPS (global positioning satellite)) and outlet types of 2208 outlets in the eight counties assembled in $2009^{(52)}$. Residential addresses were geo-coded using ArcGIS 10.0 (ESRI, Redlands, CA, USA) and assigned to Census 2000 tracts using a point-in-polygon operation within ArcGIS. The number of supermarkets within the census tract of residence was used as a measure of availability, but for the purpose of sensitivity analyses, we additionally calculated the availability in a census block group and in a 1 mile $(1.6 \mathrm{~km})$ network buffer.

\section{Perceptions of the food environment}

In order to assess how residents rated their local neighbourhood food environment, we utilized an existing questionnaire which assesses the perceived availability of healthy food in the neighbourhood ${ }^{(33,37,39,56,57)}$. We have previously reported satisfactory psychometric properties for this instrument (intra-class correlation coefficient $=$ $0 \cdot 71 ; 95 \%$ CI $0 \cdot 60,0 \cdot 80)^{(58)}$. Survey participants were asked to think of their neighbourhood as an area within a 20-min walk or about a mile from their home and asked to indicate their agreement with the following statements on a five-point Likert scale (ranging from $1=$ 'strongly agree' to $5=$ 'strongly disagree'): 'A large selection of fruits and vegetables is available in my neighbourhood', 'The fresh fruits and vegetables in my neighbourhood are of high quality' and 'A large selection of low-fat products is available in my neighbourhood'. These three questions were summed, reverse-coded and linearly transformed so that a value of 0 indicated the worst availability of healthy foods and 12 indicated the best availability. We also assessed the perceptions of general access to food shopping with a single question (four response categories 'not really a problem', 'minor problem', 'somewhat serious problem', 'very serious problem'): 'How much of a problem would you say that lack of access to adequate food shopping is in your neighbourhood?' This variable was reverse-coded to express ease of access, with a score of 0 representing poor access (i.e. very serious problem) and a score of 3 representing easy access (i.e. not really a problem).

\section{Food shopping bebaviour}

Food shopping questions queried the name and address of the store in which respondents conducted the majority of their grocery shopping and the frequency of shopping at that store. The primary grocery store address was geo-coded using ArcGIS 10.0 and matched to the aforementioned, validated database of retail food outlets ${ }^{(52)}$. Distances between the primary store and residence were calculated using the shortest street-network distance in miles based on the TIGER 2008 road network (US Census TIGER/ Line, 2008).

\section{Fruit and vegetable intake}

Several dietary behaviours were assessed with the seventeen-item Multifactor Screener applied in the 2000 National Health Interview Survey ${ }^{(59,60)}$. This short instrument queries food intake in the past month and a finite number of groups of fruits and vegetables (i.e. fruit juice, fruit, lettuce, vegetables, white potatoes, beans). It has been shown to provide reasonable estimates of true intakes of fruits and vegetables with correlations to intake assessed by $24 \mathrm{~h}$ dietary recalls and FFQ ranging from 0.6 to $0 \cdot 7^{(59)}$. We followed the recommended scoring and analyses procedures described previously for this instrument ${ }^{(60,61)}$.

\section{Statistical analyses}

Our statistical analyses were restricted to respondents with complete data. Of the 968 participants, we sequentially excluded nineteen without geospatial data because their residential address was not geo-codable, sixty-nine without data on F\&V intake, thirty who did not respond to one or more perceptions questions, one person missing food shopping frequency and eighteen missing distance to primary food store, leaving 831 for analysis. Because the distributions of shopping frequency and distance to primary store were skewed, these variables were winsorized at the 95th percentile.

The relationships between (i) the GIS-based measure of supermarket availability, (ii) perceptions of the availability of healthy foods in the neighbourhood and ease of shopping access, (iii) shopping behaviours (distance and frequency) and (iv) F\&V intake were examined through path analysis using PROC CALIS in the statistical software package SAS version 9.2. As shown in Fig. 1, in addition to the direct effects between each variable and F\&V 
intake, indirect effects were also examined. That is, we investigated if previously noted relationships between GIS-based measures of the food environment and F\&V intake ${ }^{(25,37,42-44,62)}$ were partially explained by shopping behaviours. Because the perception variables are theoretically related to one another, as are the two shopping behaviour variables, the reciprocal nature of these two sets of variables was also reflected in the model by double arrows (Fig. 1). We report standardized beta coefficients and $P$ values for paths and explained variation for endogenous variables, first for all relationships and then in a simplified version, focusing only on the statistically significant associations $(P<0 \cdot 05)$. Unlike regression models, a single path analysis model (similar to structural equation modelling) tests a theoretical model that is believed to be applicable to a general population. Thus, it does not control for factors that are considered confounders in regression analysis because it would result in an over-specification of the model $^{(62)}$.

\section{Results}

Characteristics of the study sample are presented in Table 1. Our sample largely included women (80\%), which is consistent with the prevailing culture of women generally being the household member responsible for grocery shopping. The proportion of minority participants (33\%) was representative of South Carolina. Participants were middle-aged and older (average age 57 years) and only $44 \%$ were employed, which is likely due to the reliance on listed landline phone numbers. Almost half of our sample (42\%) reported an annual household income below \$US 40000 . For $45 \%$ the highest educational attainment was a high-school degree or less. Average self-reported intake of F\&V was 4.4 servings/d. Participants reported shopping predominantly at supermarkets or large grocery stores (93\%) and the average shopping frequency was 1.7 times/ week (median $=1 \cdot 0$ times/week). Based on GIS analyses, the average distance to the primary grocery store was 9.4 miles $(15.0 \mathrm{~km}$; median $=8.0$ miles $(12.8 \mathrm{~km}))$. The majority of participants $(55 \%)$ did not have a supermarket available in their census tract. Availability of healthy foods in the neighbourhood was rated as 6.3 on a scale from 0 to 12. With respect to ease of access to food shopping, respondents generally were positive ( mean $=2 \cdot 1$ on a scale from 0 to 3 ). The study area contained 150 census tracts in eight counties, with an average of $37 \cdot 2$ square miles $\left(96 \cdot 3 \mathrm{~km}^{2}\right)$ per tract and a tract population average of about 4210. About $21 \%$ of the study population lived in areas considered urban core.

Figure 2 represents the results of the path analysis. Frequency of grocery shopping was the only factor that had a statistically significant direct effect on F\&V intake

Table 1 Descriptive characteristics of the study sample: 831 household food shoppers, residents of an eight-county region of South Carolina, USA, 2010

\begin{tabular}{|c|c|c|}
\hline & Mean or \% & SD \\
\hline \multicolumn{3}{|l|}{ Demographic characteristics } \\
\hline Age (years) & $57 \cdot 2$ & $14 \cdot 5$ \\
\hline Female & $79 \cdot 2$ & - \\
\hline Minority (African-American, Hispanic, Other) & $32 \cdot 6$ & - \\
\hline High-school education or less & $45 \cdot 2$ & - \\
\hline Low/mid income (\$US 39999 or less) & $42 \cdot 3$ & - \\
\hline Employed & $43 \cdot 5$ & - \\
\hline \multicolumn{3}{|l|}{ Dietary intake } \\
\hline Fruit and vegetable intake (servings/d) & $4 \cdot 4$ & $1 \cdot 5$ \\
\hline \multicolumn{3}{|l|}{ Food shopping behaviour } \\
\hline Distance travelled to primary grocery store (miles) & $9 \cdot 4$ & $6 \cdot 8$ \\
\hline Distance travelled to primary grocery store $(\mathrm{km})$ & $15 \cdot 0$ & $10 \cdot 9$ \\
\hline Frequency of shopping (times/week) & $1 \cdot 7$ & $1 \cdot 3$ \\
\hline \multicolumn{3}{|l|}{ GIS food environment } \\
\hline \multicolumn{3}{|l|}{ Count of supermarkets/grocery stores per census tract } \\
\hline 0 & $54 \cdot 6$ & - \\
\hline 1 & $29 \cdot 0$ & - \\
\hline 2 & $12 \cdot 8$ & - \\
\hline 3 & $2 \cdot 5$ & - \\
\hline 4 & $1 \cdot 1$ & - \\
\hline Average & 0.66 & 0.85 \\
\hline \multicolumn{3}{|l|}{ Perceptions of the food environment } \\
\hline Availability of healthy foods (range: $0-12$ ) & $6 \cdot 3$ & $3 \cdot 7$ \\
\hline Ease of shopping access (range: $0-3$ ) & $2 \cdot 1$ & $1 \cdot 1$ \\
\hline \multicolumn{3}{|l|}{ Census tract characteristics } \\
\hline Total number of census tracts & 150 & - \\
\hline Census tract area (square miles) & $37 \cdot 2$ & $49 \cdot 8$ \\
\hline Census tract area $\left(\mathrm{km}^{2}\right)$ & $96 \cdot \overline{3}$ & $129 \cdot 0$ \\
\hline Population per census tract & 4210 & 2151 \\
\hline
\end{tabular}

GIS, geographic information system.

Values are presented as mean and standard deviation or as percentage of the study population. 


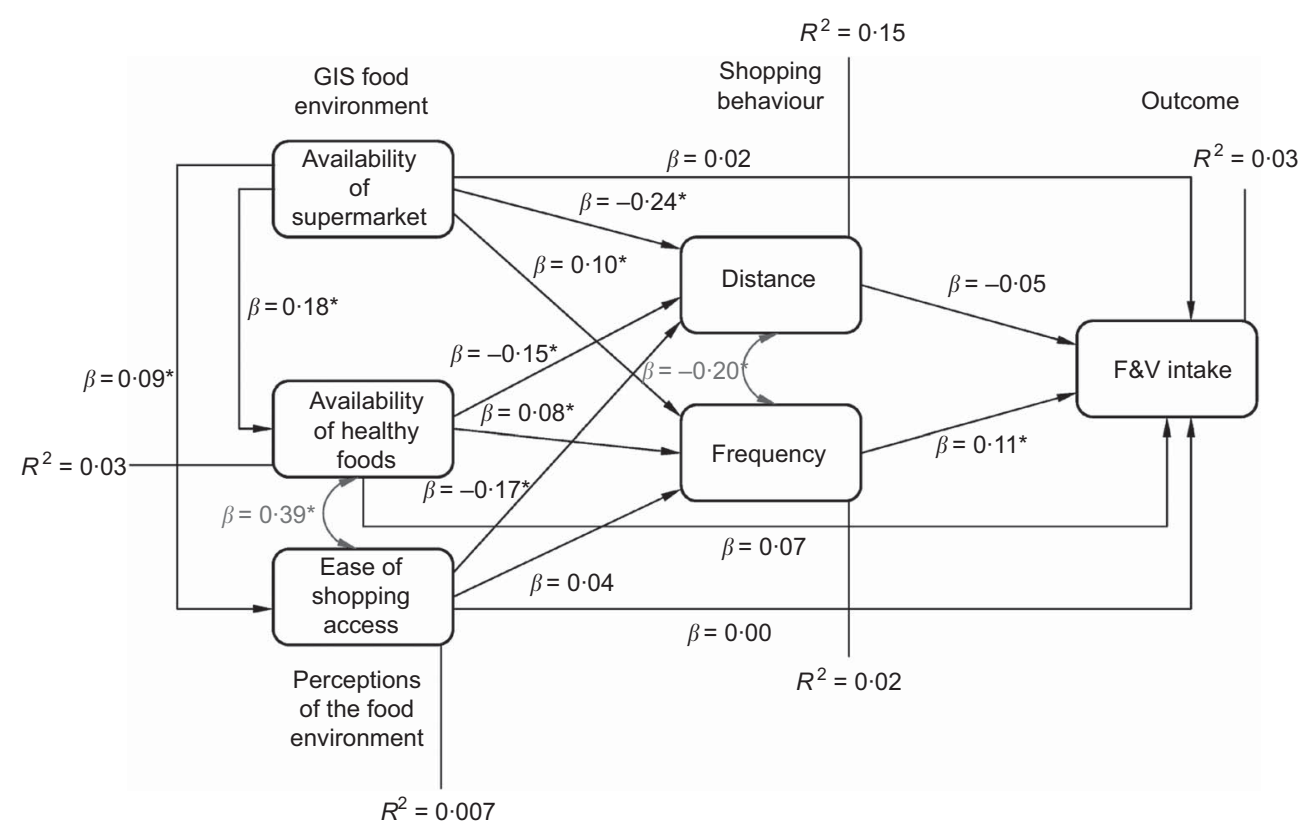

Fig. 2 Complete path analytic model of environmental influences on fruit and vegetable (F\&V) intake among 831 household food shoppers, residents of an eight-county region of South Carolina, USA, 2010. Values shown are standardized beta coefficients $(\beta)$ or explained variation $\left(R^{2}\right)$; ${ }^{*}$ indicates statistical significance at $P<0.05$ (GIS, geographic information system)

$(\beta=0 \cdot 11)$, i.e. a higher shopping frequency was associated with higher intake of F\&V. Contrary to our hypothesis, no other direct influences on $\mathrm{F} \& \mathrm{~V}$ intake were observed. In totality, all variables in the path analysis explained only $3 \%$ of the variation in $\mathrm{F} \& \mathrm{~V}$ intake.

The number of supermarkets per tract was significantly and positively associated with perceived availability of healthy foods $(\beta=0 \cdot 18)$ and with perceived ease of access $(\beta=0 \cdot 09)$. However, supermarket availability explained only $3 \%$ of the variability in perceived healthy food availability and less than $1 \%$ of the perceived ease of access. The two perception measures were significantly and positively correlated with each other $(\beta=0 \cdot 39)$.

Focusing on the other tested relationships, we found that the number of supermarkets per tract was inversely associated with distance to the utilized grocery store $(\beta=-0 \cdot 24)$, i.e. a greater amount of supermarkets in the census tract of residence was associated with a smaller distance travelled to the primary food store. Furthermore, supermarket availability was positively associated with the frequency of shopping $(\beta=0 \cdot 10)$. We also observed significant and inverse associations of both measures of perception with distance to the utilized primary grocery store $(\beta=-0 \cdot 15$ and $-0 \cdot 17$, respectively). There was a significant direct effect of perceived availability of healthy foods on shopping frequency $(\beta=0 \cdot 08)$, but no direct effect of ease of access on shopping frequency. Frequency of shopping was also significantly and inversely correlated with distance to the primary food store $(\beta=-0 \cdot 20)$. In totality, the GIS-based and the perception-based measures of the food environment explained $15 \%$ of the variation in distance to the primary food store but only $2 \%$ of the variation in food shopping frequency. Figure 3 is a simplified representation of the full path analytic results presented in Fig. 2, containing only the statistically significant paths.

Table 2 presents the results from the full path model in terms of the partitioned direct and indirect effects and the total effects of the three primary variables. Although availability of supermarkets did not have a direct effect on F\&V intake, it did have a statistically significant indirect effect (through the other variables included in the model). However, because the total effect was not significant $(\beta=0 \cdot 058, P=0 \cdot 09)$ we concluded that, overarchingly, supermarket availability was not a significant contributor to F\&V intake. Perceived availability of healthy foods did not have a significant direct effect on F\&V intake; however, it did have a statistically significant indirect effect as well as a significant total effect. These findings suggest that perceptions of healthy food availability are an important element of understanding F\&V intake. Lastly, perceived ease of shopping access did not have a statistically significant direct, indirect or total effect on F\&V intake.

\section{Discussion}

As recently reviewed by Caspi et $a l^{(63)}$, a substantial number of studies have reported positive associations of the availability of supermarkets in the neighbourhood, as assessed by GIS methods, on intake of fruits and vegetables ${ }^{(37,42-44,62)}$. 


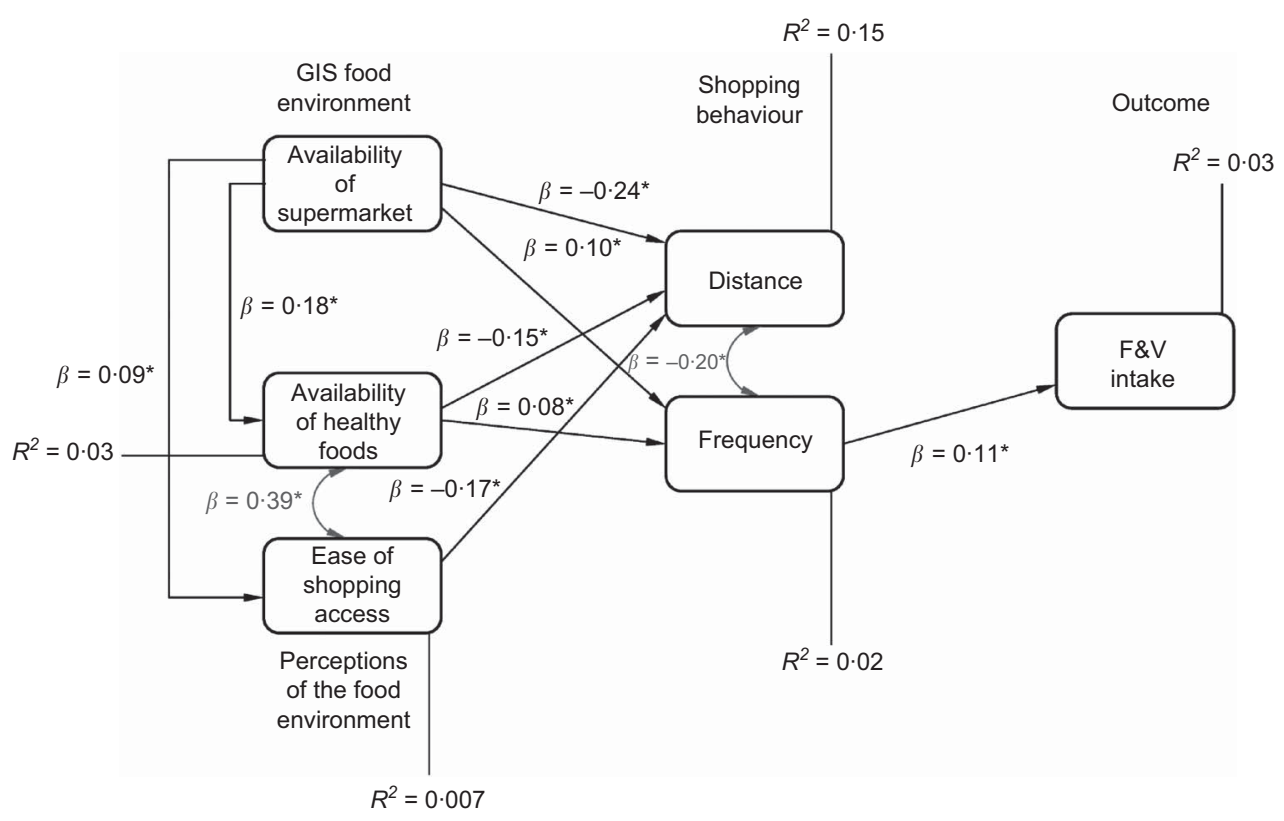

Fig. 3 Simplified path analytic model of environmental influences on fruit and vegetable (F\&V) intake among 831 household food shoppers, residents of an eight-county region of South Carolina, USA, 2010. Values shown are standardized beta coefficients $(\beta)$ or explained variation $\left(R^{2}\right)$; ${ }^{*}$ indicates statistical significance at $P<0.05$ (GIS, geographic information system)

Table 2 Partitioning the effects of supermarket availability, perceived availability of health foods and ease of shopping access on fruit and vegetable intake from the full path model, expressed as standardized beta coefficients, among 831 household food shoppers, residents of an eight-county region of South Carolina, USA, 2010

\begin{tabular}{lccc}
\hline Variable & Direct effect & Indirect effect & Total effect \\
\hline Supermarket availability & 0.0195 & $0.0385^{\star}$ & $0 \cdot 0580$ \\
Perception of healthy food availability & 0.0670 & $0.0160^{\star}$ & $0.0830^{\star}$ \\
Perception of ease of shopping access & -0.000732 & 0.0130 & 0.0123 \\
\hline
\end{tabular}

${ }^{\star} P<0.05$.

In contrast to our hypothesis, our study is one of the few showing null findings ${ }^{(45,46,64)}$, as we did not find evidence for a direct association between the availability of supermarkets in the neighbourhood (using validated data on food retail stores) and F\&V intake. In a series of sensitivity analyses our results were entirely robust to variations in what constituted a neighbourhood (e.g. changing boundaries from census tract to block group or to street-network based buffer) or the choice of access measure (e.g. replacing the supermarket availability measure with a measure of accessibility (which weights availability by distance)) ${ }^{(65)}$. One potential explanation for the lack of an association between supermarket availability and F\&V intake may be that our study population was very mobile ( $94 \%$ car ownership) and $97 \%$ did not shop at the closest supermarket. Our study did, however, find that availability of supermarkets exerted significant indirect effects through the other variables in the model, including distance to the utilized store. While the absence of a total effect of supermarket availability suggests that this food environment characteristic did not contribute to explaining F\&V intake in our study sample, it is important to point out that our sample size was limited and thus our model needs replication in larger studies.

A number of studies have previously demonstrated associations between a variety of subjective measures of perceptions of the food environment and dietary intake, generally finding the availability of healthy foods in the neighbourhood as reported by the residents to be associated with more healthful dietary behaviours ${ }^{(34-37,47,64,66,67)}$. Contrary to these findings and our hypotheses, no direct association of perceptions of healthy food availability or ease of access was observed with F\&V intake in our sample. One potential explanation for this discrepancy may be that the measures of perceptions used in previous studies reflected some of the information contained in food shopping behaviour, which we were able to parse out into independent and relative influences. While perceived ease of access did not have a statistically significant total effect on F\&V intake in our study, perceived availability of healthy foods in the neighbourhood exerted statistically significant both indirect and total effects on F\&V intake, indicating that this measure was useful in explaining 
F\&V intake. Furthermore, we observed significant positive associations between the GIS-based supermarket availability and the perceptions, and - importantly strong associations of both these measures of the food environment with food shopping behaviours. This suggests that both the reality of the built environment (i.e. the physical presence of supermarkets) and the perceptions of the food shoppers (i.e. the availability of healthy foods and ease of access) seem to be important influences on the choice of a grocery store and the frequency of food shopping.

To date, very few epidemiological studies have explicitly considered spatial attributes of food shopping behaviours in relation to dietary intake or obesity ${ }^{(22,23,25-32)}$. We ascertained information on the location of the primarily utilized food store and thus were able to use the distance to the primary food store as a measure of realized access. In contrast, most other studies have been limited to a measure of potential access, using distance to the nearest store without consideration of whether the store is being uti$\operatorname{lized}^{(34,44,45,64,67-71)}$. Consistent with our hypotheses, we found that GIS-based availability of supermarkets, perceived availability of healthy foods and shopping frequency were all inversely related to distance to the utilized store. A study of French residents reported that persons who shopped far away from home had a slightly higher BMI and waist circumference than those shopping more proximally ${ }^{(26)}$. In contrast, a recent study of women in North Carolina receiving food assistance did not find an association between distance to utilized supermarkets and $\mathrm{BMI}^{(28)}$. While not focused on BMI, our study similarly did not find a direct association of distance with F\&V intake, but an indirect association through shopping frequency.

In the present study, individuals who shopped more frequently at their primary grocery store reported a higher intake of F\&V. In fact, frequency of food shopping was the only factor directly associated with F\&V consumption in the path analytic model. This finding and the inverse association of frequency with distance to utilized store is consistent with an economic model of food shopping in which a consumer would balance the travel and time cost of distance to the utilized store against the need to obtain a specific product and - in the case of fresh produce - the limited ability to store it ${ }^{(24)}$. Considering our findings both on distance to utilized store and shopping frequency, our study suggests that for perishable goods such as fresh fruits and vegetables, increasing opportunities for more frequent purchases through neighbourhood markets or produce trucks may in fact motivate higher consumption.

There are a number of limitations to our study. Similar to the majority of research in this field ${ }^{(15)}$, our study was cross-sectional in nature which potentially limits the validity of causal inference because of reverse causality. For instance, it is possible that individuals who consume a healthier diet may also be more aware of a healthy environment. Our study relied on spatial information on food shopping for only a single food store, which was reported as the primary food store. Moreover, distance measures calculated to the store were computed assuming that the departure point was home, which fortunately was true for $83.4 \%$ of the population. With respect to the GIS-based food environment, even though we had information on the availability of other store types, we limited this analysis to supermarkets because we wished to keep our conceptual model and analyses focused on our hypotheses. Thus, we cannot exclude the possibility that other attributes of the food environment, such as the presence of fast-food outlets, could have independent and direct influences of F\&V intake. The field census survey on food environment in the current study was conducted in 2009 and the survey data were collected in 2010. Thus, the mismatch in years of data collection will have likely introduced a small amount of error. Lastly, this conceptual model is a first attempt and in that sense exploratory, intended to focus on and integrate the three dimensions of the food environment, each of which have been evaluated separately in the published literature to date. We clearly did not include information on psychosocial measures, such as self-efficacy or social support ${ }^{(50)}$, or economic influences ${ }^{(47)}$ which certainly contributed to the low overall percentage of explained variation in F\&V intake.

In terms of strengths, our study advances previous work by utilizing validated GIS-based data on the availability of supermarkets with state-of-the-art GIS analyses, rather than relying exclusively on secondary data which have been shown to harbour substantial inaccuracies ${ }^{(52)}$. Furthermore, the study area included urban areas and a large number of rural communities, which have not been studied in the past ${ }^{(34,62)}$. Assessment of perceptions of the food environment was based on a validated questionnaire $^{(39,56,58)}$. Furthermore, our study is one of the first to assess food shopping behaviours within a structured interview, including not only the location of the primary grocery store but the frequency of shopping, both of which were incorporated in our conceptual model $^{(25-28)}$. Lastly, our study differs from most previous work in the field of food environment research in that we used path analysis to study the complex interrelationships of multiple environmental attributes affecting dietary intake, thereby modelling and quantifying the relative influence of each factor. Path analysis allows researchers to test theoretical models and causal relationships between a multitude of observed variables, collectively. To the best of our knowledge, only two studies using a similarly complex conceptual framework to ours have been published, albeit using structural equation modelling ${ }^{(16,62)}$.

Our results are important in the context of recently implemented US policies on food access, which specifically target the improvement of spatial access to food outlets supporting healthful food choices, such as supermarkets or large grocery stores, or modifications of smaller stores to 
support healthier food choices ${ }^{(10)}$. While our study did not observe a direct influence of purely spatial availability of supermarkets in the neighbourhood on F\&V intake, the availability of supermarkets exerted an indirect effect through associations with both shopping behaviours and perceptions of the environment. Moreover, through its indirect and inverse association with shopping frequency, distance to the utilized food store contributed to F\&V intake. This suggests that ongoing efforts to increase local opportunities to purchase fresh produce at neighbourhood markets or through produce trucks may in fact be promising strategies to increase $F \& V$ intake in the general population. Our findings furthermore suggest that strategies focusing exclusively on increased supermarket availability would likely only be effective in changing $F \& V$ intake if they lead to increased perceptions of healthy food availability among residents, reduced distance to the utilized grocery store or more frequent food shopping. In conclusion, our study suggests an important role of food shopping behaviour, especially shopping frequency, on intake of $\mathrm{F} \& \mathrm{~V}$ in a conceptual model that included multiple environmental attributes measured objectively as well as subjectively.

\section{Acknowledgements}

Sources of funding: This project was supported by grant R21CA132133-02S1 from the National Cancer Institute. The contents of this article are solely the responsibility of the authors and do not necessarily represent the official views of the National Cancer Institute or the National Institutes of Health. The National Cancer Institute had no role in the design, analysis or writing of this article. Conflicts of interest: There are no conflicts of interest to disclose. Authors' contributions: A.D.L. developed the idea for this manuscript, provided oversight for the statistical analyses and wrote the manuscript. B.A.B. outlined the statistical analyses and contributed to the editing of the manuscript. J.D.H. geo-coded the data, conducted GIS-based data management and reviewed the manuscript. T.L.B. completed the statistical analyses and contributed to the editing of the manuscript. N.C., C.E.B. and D.A.F. reviewed and edited the manuscript and contributed to the discussion. All authors read and approved the final manuscript. Acknowledgements: The authors would like to thank Michele Nichols for data management and initial statistical programming.

\section{References}

1. Ogden CL, Carroll MD, Kit BK et al. (2012) Prevalence of obesity and trends in body mass index among US children and adolescents, 1999-2010. JAMA 307, 483-490.

2. Flegal KM, Carroll MD, Kit BK et al. (2012) Prevalence of obesity and trends in the distribution of body mass index among US adults, 1999-2010. JAMA 307, 491-497.
3. Woolf SH \& Nestle M (2008) Do dietary guidelines explain the obesity epidemic? Am J Prev Med 34, 263-265.

4. Kant AK \& Graubard BI (2006) Secular trends in patterns of self-reported food consumption of adult Americans: NHANES 1971-1975 to NHANES 1999-2002. Am J Clin Nutr 84, 1215.

5. Nielsen SJ, Siega-Riz AM \& Popkin BM (2002) Trends in food locations and sources among adolescents and young adults. Prev Med 35, 107-113.

6. Larson N \& Story M (2009) A review of environmental influences on food choices. Ann Behav Med 38, 56-73.

7. Walker RE, Keane CR \& Burke JG (2010) Disparities and access to healthy food in the United States: a review of food deserts literature. Health Place 16, 876-884.

8. Ver Ploeg M, Breneman V, Farrigan T et al. (2011) Access to Affordable and Nutritious Food - Measuring and Understanding Food Deserts and Their Consequences: Report to Congress. Report no. AP-036. Washington, DC: US Department of Agriculture, Economic Research Service.

9. Centers for Disease Control and Prevention (2009) State Indicator Report on Fruits and Vegetables. http://www. fruitsandveggiesmatter.gov/downloads/StateIndicatorReport 2009.pdf (accessed October 2010).

10. US Department of Health and Human Services (2010) Health Food Financing Initiative. http://www.hhs.gov/ news/press/2010pres/02/20100219a.html (accessed April 2011).

11. US Department of Health and Human Services, Centers for Disease and Control and Prevention (2011) Children's Food Environment State Indicator Report, 2011. http://www. cdc.gov/obesity/downloads/ChildrensFoodEnvironment.pdf (accessed March 2012).

12. US Department of Agriculture, Economic Research Service (2011) USDA Food Desert Locator. http://www.ers.usda. gov/data/fooddesert (accessed July 2011).

13. US Department of Agriculture, Economic Research Service (2011) USDA Food Environment Atlas. http://www.ers. usda.gov/FoodAtlas/ (accessed July 2011).

14. McKinnon RA, Reedy J, Morrissette MA et al. (2009) Measures of the food environment a compilation of the literature, 1990-2007. Am J Prev Med 36, 124-133.

15. Caspi CE, Sorensen G, Subramanian SV et al. (2012) The local food environment and diet: a systematic review. Health Place 18, 1172-1187.

16. Zenk SN, Schulz AJ, Hollis-Neely T et al. (2005) Fruit and vegetable intake in African Americans income and store characteristics. Am J Prev Med 29, 1-9.

17. Baranowski T, Cooper DM, Harrell J et al. (2006) Presence of diabetes risk factors in a large US eighth-grade cohort. Diabetes Care 29, 212-217.

18. Yoo S, Baranowski T, Missaghian M et al. (2006) Foodpurchasing patterns for home: a grocery store-intercept survey. Public Health Nutr 9, 384-393.

19. French SA, Wall M, Mitchell NR et al. (2009) Annotated receipts capture household food purchases from a broad range of sources. Int J Behav Nutr Phys Act 6, 37.

20. French SA, Shimotsu ST, Wall M et al. (2008) Capturing the spectrum of household food and beverage purchasing behavior: a review. J Am Diet Assoc 108, 2051-2058.

21. Laska MN, Graham DJ, Moe SG et al. (2010) Young adult eating and food-purchasing patterns food store location and residential proximity. Am J Prev Med 39, 464-467.

22. Hearst MO, Pasch KE \& Laska MN (2012) Urban $v$. suburban perceptions of the neighbourhood food environment as correlates of adolescent food purchasing. Public Health Nutr 15, 299-306.

23. Krukowski RA, McSweeney J, Sparks C et al. (2012) Qualitative study of influences on food store choice. Appetite 59, 510-516. 
24. Bawa K \& Ghosh A (1999) A model of household grocery shopping behavior. Mark Lett 10, 149-160.

25. Rose D \& Richards R (2004) Food store access and household fruit and vegetable use among participants in the US Food Stamp Program. Public Health Nutr 7, 1081-1088.

26. Chaix B, Bean K, Daniel M et al. (2012) Associations of supermarket characteristics with weight status and body fat: a multilevel analysis of individuals within supermarkets (RECORD study). PLoS One 7, e32908.

27. Drewnowski A, Aggarwal A, Hurvitz PM et al. (2012) Obesity and supermarket access: proximity or price? $A m \mathrm{~J}$ Public Health 102, e74-e80.

28. Jilcott SB, McGuirt JT, Carr LJ et al. (2013) Associations between body mass index, shopping behaviors, amenity density, and characteristics of the neighborhood food environment among female adult Supplemental Nutrition Assistance Program (SNAP) participants in Eastern North Carolina. Ecol Food Nutr 51, 526-541.

29. Laska MN, Hearst MO, Forsyth A et al. (2010) Neighbourhood food environments: are they associated with adolescent dietary intake, food purchases and weight status? Public Health Nutr 13, 1757-1763.

30. Jilcott SB, Wade S, McGuirt JT et al. (2011) The association between the food environment and weight status among eastern North Carolina youth. Public Health Nutr 14, 1610-1617.

31. D'Angelo H, Suratkar S, Song HJ et al. (2011) Access to food source and food source use are associated with healthy and unhealthy food-purchasing behaviours among low-income African-American adults in Baltimore City. Public Health Nutr 14, 1632-1639.

32. Gustafson A, Christian JW, Lewis S et al. (2013) Food venue choice, consumer food environment, but not food venue availability within daily travel patterns are associated with dietary intake among adults, Lexington Kentucky 2011. Nutr J 12, 17.

33. Moore LV, Diez Roux AV \& Brines S (2008) Comparing perception-based and Geographic Information System (GIS)-based characterizations of the local food environment. J Urban Health 85, 206-216.

34. Sharkey JR, Johnson CM \& Dean WR (2010) Food access and perceptions of the community and household food environment as correlates of fruit and vegetable intake among rural seniors. BMC Geriatr 10, 32.

35. Osypuk TL, Diez Roux AV, Hadley C et al. (2009) Are immigrant enclaves healthy places to live? The Multi-ethnic Study of Atherosclerosis. Soc Sci Med 69, 110-120.

36. Inglis V, Ball K \& Crawford D (2008) Socioeconomic variations in women's diets: what is the role of perceptions of the local food environment? J Epidemiol Community Health 62, 191-197.

37. Moore LV, Diez-Roux AV, Nettleton JA et al. (2008) Associations of the local food environment with diet quality - a comparison of assessments based on surveys and geographic information systems: the multi-ethnic study of atherosclerosis. Am J Epidemiol 167, 917-924.

38. Moore LV, Diez-Roux AV \& Franco M (2012) Measuring availability of healthy foods: agreement between directly measured and self-reported data. Am J Epidemiol 175, 1037-1044.

39. Mujahid MS, Diez-Roux AV, Morenoff JD et al. (2007) Assessing the measurement properties of neighborhood scales: from psychometrics to ecometrics. Am J Epidemiol 165, 858-867.

40. Freedman DA \& Bell BA (2009) Access to healthful foods among an urban food insecure population: perceptions versus reality. J Urban Health 86, 825-838.

41. Keita AD, Casazza K, Thomas O et al. (2011) Neighborhood perceptions affect dietary behaviors and diet quality. $J$ Nutr Educ Behav 43, 244-250.
42. Morland K, Wing S \& Diez-Roux A (2002) The contextual effect of the local food environment on residents' diets: the atherosclerosis risk in communities study. Am J Public Health 92, 1761-1767.

43. Lamichhane AP, Mayer-Davis EJ, Puett R et al. (2012) Associations of built food environment with dietary intake among youth with diabetes. I Nutr Educ Behav 44, 217-224.

44. Laraia BA, Siega-Riz AM, Kaufman JS et al. (2004) Proximity of supermarkets is positively associated with diet quality index for pregnancy. Prev Med 39, 869-875.

45. Bodor JN, Rose D, Farley TA et al. (2008) Neighbourhood fruit and vegetable availability and consumption: the role of small food stores in an urban environment. Public Health Nutr 11, 413-420.

46. An R \& Sturm R (2012) School and residential neighborhood food environment and diet among California youth. Am J Prev Med 42, 129-135.

47. Giskes K, van Lenthe FJ, Brug J et al. (2007) Socioeconomic inequalities in food purchasing: the contribution of respondent-perceived and actual (objectively measured) price and availability of foods. Prev Med $\mathbf{4 5}$, $41-48$.

48. Lucan SC \& Mitra N (2012) Perceptions of the food environment are associated with fast-food (not fruit-andvegetable) consumption: findings from multi-level models. Int J Public Health 57, 599-608.

49. Susser M \& Susser E (1996) Choosing a future for epidemiology: II. From black box to Chinese boxes and eco-epidemiology. Am J Public Health 86, 674-677.

50. Sallis JF, Owen N \& Fisher EB (2008) Ecological models of health behavior. In: Health Behavior and Health Education: Theory, Research, and Practice, 4th ed., pp. 465-484 [K Glanz, BK Rimer and K Viswanath, editors]. San Francisco, CA: Jossey-Bass.

51. Bandura A (2004) Health promotion by social cognitive means. Health Educ Behav 31, 143-164.

52. Liese AD, Colabianchi N, Lamichhane AP et al. (2010) Validation of 3 food outlet databases: completeness and geospatial accuracy in rural and urban food environments. Am J Epidemiol 172, 1324-1333.

53. American Association for Public Opinion Research (2009) Standard Definitions, Final Dispositions of Case Codes and Outcome Rates for Surveys. Deerfield, IL: American Association for Public Opinion Research.

54. Hu SS, Balluz L, Battaglia MP et al. (2011) Improving public health surveillance using a dual-frame survey of landline and cell phone numbers. Am J Epidemiol 173, 703-711.

55. Liese AD, Barnes TL, Lamichhane AP et al. (2013) Characterizing the food retail environment: impact of count, type and geospatial error in two secondary data sources. J Nutr Educ Behav 45, 435-442.

56. Echeverria SE, Diez-Roux AV \& Link BG (2004) Reliability of self-reported neighborhood characteristics. J Urban Health 81, 682-701.

57. Moore LV, Diez-Roux AV, Nettleton JA et al. (2009) Fast-food consumption, diet quality, and neighborhood exposure to fast food: the multi-ethnic study of atherosclerosis. Am J Epidemiol 170, 29-36.

58. Ma X, Barnes T, Freedman DA et al. (2013) Test-retest reliability of a questionnaire measuring perceptions of neighborhood food environment. Health Place 21C, 65-69.

59. Thompson FE, Midthune D, Subar AF et al. (2004) Performance of a short tool to assess dietary intakes of fruits and vegetables, percentage energy from fat and fibre. Public Health Nutr 7, 1097-1105.

60. Thompson FE, Midthune D, Subar AF et al. (2005) Dietary intake estimates in the National Health Interview Survey, 
2000: methodology, results, and interpretation. J Am Diet Assoc 105, 352-363.

61. National Cancer Institute (2013) Multifactor Screener: Scoring Procedures. http://appliedresearch.cancer.gov/surveys/nhis/ multifactor/scoring.html (accessed October 2013).

62. Hermstad AK, Swan DW, Kegler MC et al. (2010) Individual and environmental correlates of dietary fat intake in rural communities: a structural equation model analysis. Soc Sci Med 71, 93-101.

63. Caspi CE, Kawachi I, Subramanian SV et al. (2012) The relationship between diet and perceived and objective access to supermarkets among low-income housing residents. Soc Sci Med 75, 1254-1262.

64. Williams L, Ball K \& Crawford D (2010) Why do some socioeconomically disadvantaged women eat better than others? An investigation of the personal, social and environmental correlates of fruit and vegetable consumption. Appetite 55, 441-446.

65. Van Meter ME, Lawson AB, Colabianchi N et al. (2011) Spatial accessibility and availability measures and statistical properties in the food environment. Spat Spatiotemporal Epidemiol 2, 35-47.
66. Lucan SC, Barg FK, Karasz A et al. (2011) Concepts of healthy diet among urban, low-income, African Americans. J Community Health 37, 754-762.

67. Gustafson AA, Sharkey J, Samuel-Hodge CD et al. (2011) Perceived and objective measures of the food store environment and the association with weight and diet among low-income women in North Carolina. Public Health Nutr 14, 1032-1038.

68. Michimi A \& Wimberly MC (2010) Associations of supermarket accessibility with obesity and fruit and vegetable consumption in the conterminous United States. Int $J$ Health Geogr 9, 49.

69. Thornton LE, Crawford DA \& Ball K (2010) Neighbourhood-socioeconomic variation in women's diet: the role of nutrition environments. Eur J Clin Nutr 64, 1423-1432.

70. Pearce A, Kirk C, Cummins S et al. (2009) Gaining children's perspectives: a multiple method approach to explore environmental influences on healthy eating and physical activity. Health Place 15, 614-621.

71. Pearson T, Russell J, Campbell MJ et al. (2005) Do 'food deserts' influence fruit and vegetable consumption? - A cross-sectional study. Appetite 45, 195-197. 